\title{
LEXIKON DER ROMANISTISCHEN LINGUISTIK (LRL). Edité par Günter Holtus - Michael Metzeltin - Christian Schmitt. Volume VI,1. Aragonés/Navarro, Español, Asturiano/Leonés. Max Niemeyer Verlag, Tübingen 1992, págs. XXXVIII+708
}

1. El Diccionario enciclopédico de lingǘstica románica (LRL) es un compendio general de todo el saber romanístico sobre la génesis, el desarrollo y el estado actual de las lenguas románicas. La obra consta de ocho volúmenes, de los cuales han aparecido, hasta ahora, los que tratan de las lenguas románicas desde el Renacimiento hasta nuestros días, con excepción del volumen reservado al gallego y portugués. Esperamos, por tanto, con gran interés la aparición del segundo volumen, dedicado al latín y al desarrollo de las lenguas románicas desde la Edad Media hasta el Renacimiento.

Sobre más de un punto, el LRL se muestra innovador, revolucionario o por lo menos sorprendente respecto a la mayoría de los manuales de lingüística románica. Así, el francoprovenzal, cuya existencia e independencia fue constatada por primera vez por G. I. Ascoli en el Archivio Glottologico Italiano III (1878), está incorporado al dominio francés (vol. $\mathrm{V}, 1)$. El catalán parece tomar parte de la esfera galoromance: está tratado en el mismo volumen que el occitano. Nos sorprende también el presente volumen: al lado de español están como lenguas románicas el aragonés/navarro y el asturiano/leonés. Estamos acostumbrados a ver estas dos realidades romances como dialectos del español.

2. Por su estructura el presente volumen sustancialmente no difiere de los volúmenes sobre el italiano, corso, sardo (LRL IV) y francés (LRL V,1) que tuve ya ocasión de reseñar en la Revue de Linguistique Romane, respectivamente tomos 54 y 56. Pero sí en un detalle a tener en cuenta. En los dos volúmenes mencionados - lamentablemente - muchas aportaciones (en el volumen francés la mitad) están escritas en alemán. Es comprensible: la obra se escribió en un ambiente universitario alemán y está destinada, según mi opinión, sobre todo al ambiente estudiantil alemán. Con todo, como la consultarán romanistas de varios países me parece más que razonable escoger el español para tratar temas hispánicos. En nuestro volumen, de las 51 aportaciones sólo 12 están en alemán: además del capítulo introductorio sobre las lenguas de la Península Ibérica y su difusión aun Lengua hablada y lengua escrita, Lengua y sexos, Jergas, Lingüística y valoración, Lengua y escritura, Antroponimia, Gramaticografia y, de los capítulos sobre las áreas lingüísticas hispanohablantes, los del español en las Islas del Caribe y sobre el leonés.

De los casi cincuenta colaboradores, y hay entre ellos verdaderos maestros de nuestra ciencia, la mitad provienen del mundo universitario hispánico e hispanoamericano. Estos datos hacen innecesarias mis excusas: mi reseña consiste en unas observaciones muy parciales, concierne a los campos que me resultan más familiares. Me empuja, más que 
otro, el deseo de atraer la atención de los estudiantes de español porque les considero - el precio de los volúmenes a parte - verdaderos destinatarios del LRL.

3. El volumen está introducido por el capítulo sobre las lenguas románicas en la Península Ibérica y su difusión en la mejor tradición de Wartburg y Baldinger, claro, a distancia de decenios. En él están presentadas, sumariamente, todas las lenguas románicas de la Península y de las Américas.

Los tratados reservados al español (págs. 55-651) podrían ser agrupadas en algunas unidades más amplias:

- sonidos, sus valores, su grafia;

- formas, sus valores, su funcionamiento;

- vocablos, sus valores semánticos y estilísticos;

- toponimia y antroponimia;

- sociolingüística;

- historia de la lengua;

- áreas lingüísticas del español, dialectología, modalidades hispano-hablantes.

4. El área de fonética y fonemática presenta la situación actual con mucha claridad. Es sabido que el español, fonológicamente, posee cinco fonemas, es decir, no distingue dos fonemas en las vocales medianas. Pero, según Navarro Tomás, hay distinciones fonéticas. El autor por el contrario, basándose en sus propias investigaciones constata que las diferencias entre los grados de apertura de las vocales medianas, abiertas, cerradas, son pequeñas. Además, no se produce la pretendida distribución complementaria, es decir, no hay variantes posicionales. Son importantes las observaciones sobre realizaciones de la $/ \mathrm{s} / \mathrm{y}$ sobretodo valiosas las de la entonación en español.

5. De las formas y de su funcionamiento se ocupan los capítulos bajo los títulos de flexión, morfosintaxis y sintaxis. Es decir, los de la parte central de cada gramática.

El capítulo titulado "Flexión" se ocupa de la morfología flexiva (declinación, conjugación y comparación). La presentación es exhaustiva, tradicional. Por eso no nos sorprende encontrar la clásica nomenclatura como la de superlativo, aunque la autora misma dice muy exactamente que el "superlativo absoluto señala una cualidad en su máximo grado sin relacionar el sustantivo en cuestión con otros sustantivos" (p. 82). Es muy probable que la lucha contra el término "superlativo" (cuando es elativo) sea una lucha contra los molinos de viento. La gran responsable es la lengua latina que, formalmente, no distinguía entre el grado más alto y el grado muy alto de una cualidad. Es curioso, en el caso del español, descuidar tal distinción; el español dispone de una gran escala para formar elativos. Piénsese al Estaba más que rebién pagado de Sancho (El Quijote I/23) y a la escena de la dolorosísima dueñisima (ib. II/38), cuyo ejemplo es una verdadera provocación lingüística cuando se hable de elativo. Una observación: no hay, casi, citas de obras literarias, ni hay refranes o proverbios. Parece ser que los ejemplos que arrojan luz son propios de las gramáticas y de los gramáticos. 
Siempre en lo que concierne al elativo: es dificil creer que formas como celebérrimo, sapientísimo o ubérrimo formen parte del lenguaje coloquial, como se nos asegura en la página 82.

El capítulo "Flexión" tendría que tratar sólo el lado formal, pero es obvio que algunas veces no es posible evitar observaciones de índole semántica o del uso, es decir sintácticas. En las páginas reservadas al verbo están presentados los paradigmas verbales, hay anotaciones muy útiles sobre las alternancias vocálicas y consonánticas, sobre las diferencias en cuanto a la forma del participio, como abstracto/abstraido, que actualmente es también semántico. No me parece acertado el título de un sub-capítulo "Tiempos perifrásticos" ya que la autora habla de las perífrasis verbales; las cuales merecerian más de unas pocas líneas $\mathrm{y}$, sobretodo, es un problema sintáctico, tratado más acertadamente en el capítulo sobre la sintaxis (p. 162). La cuestión es siempre la misma: hablando de forma, incluir o no el examen sintáctico.

Los capítulos sobre la morfosintaxis y la sintaxis se ocupan, respectivamente, del sintagma y de la oración, complementándose armónicamente. El autor del primero con su conocida maestría presenta el sintagma de manera muy original: hace distinción entre lexía, torre de marfil, y sintagma (= construcción sintáctica no memorizada), torre de ladrillos. La base de su tratación son las transformaciones. Claro, muy prudentemente creeriamos que cada transformación, es decir, cada alteración, por insignificante que pueda parecer, se refleja también en la alteración del significado de la enunciación: Empezaba a llover. No me atrevi a salir puede dar No me atreví a salir porque empezaba a llover o por la lluvia. Con la subordinada explícita se expresa un matiz aspectual que le falta al sustantivo. Son valiosas las anotaciones sobre las partículas negativas, como en puede salir/no puede salir; puede no salir/no puede no salir.

La a ante un objeto $N^{2}$ (p. 153), es un verdadero estudio minúsculo del fenómeno. No es sólo del español, ya que lo conoce el italiano coloquial de algunas regiones y, aunque con otra preposición, el rumano. Aprendemos de este tratado que la cuestión no está resuelta del todo, o, por lo menos, que ya no es suficiente referirse únicamente al ${ }^{+}$animado como, en general, aprendemos en las gramáticas. El docto autor muestra con óptimos ejemplos que un papel importante lo juega la más o menos pronunciada especificidad: tener hijos/tener dos hijos/tener a dos hijos enfermos. Cita, para convalidar su tesis, de un mismo artículo en el ABC: El Papa ordena nuevos sacerdotes/Juan Pablo II ordenó a once diáconos. Están en juego, aquí, además del objeto, los diferentes paradigmas verbales.

El capítulo abunda en observaciones importantes, también de naturaleza práctica: se afirma, por ejemplo, que el se (genérico) no se puede combinar con el se reflexivo: ${ }^{*}$ si se se levanta temprano tiene que sonar si uno se levanta temprano. El italiano que tiene el mismo problema (el francés no) lo resuelve con la disimilación a distancia: *se si si alza di buon'ora $\rightarrow$ se ci si alza di buon'ora; es posible también se uno si alza di buon'ora. 
El autor dedicó una atención particular al sintagma adjetival; es el eterno problema de la posición del adjetivo: la madrileña calle de Serrano, ejemplo sólo aparentemente contrario a la regla de las buenas gramáticas: explicativo/especificativo. En este campo parece no bastante claro el paso, (p. 156), El chico que llegó ayer es mi primo con la proposición relativa entre comillas para el valor explicativo; un ejemplo con el sujeto en plural estaría, quizás, más claro. Son importantes también las notas sobre restricción semántica; pero, dice el autor, una sinécdoque permite un hombre con la cara fea y un hombre feo de cara, lo que no es posible en *una chica verde de sombrero.

El capítulo sobre la sintaxis está reservado a la oración simple y a la oración compleja. El autor delimita, en primer lugar, la oración y la frase; ésta, sin verbo en forma personal. En tratando la diferencia entre la oración compleja, pone en evidencia que en la tradición gramatical española el término de proposición es igual al de subordinada. Se evita el término de período, pero se usa en el sentido que lo conoce Lope Blanch, El concepto de oración en la lingüistica española. Están presentados también otros puntos de vista sobre la oración, como el funcionalista de la escuela de Oviedo (Alarcos Llorach).

En cuanto a la oración simple se constata muy justamente que es el sujeto el único elemento que fije su relación mediante la concordancia con el verbo (p.162). El autor pone en primer plano las perifrasis verbales: algunas sirven para expresar nociones de aspecto preferiríamos decir de Aktionsart, de modo de acción verbal; hay otras perífrasis donde el verbo (semi)auxiliar comenta la acción verbal como en suele pasar por aquí, acertó a pasar por aqui. En tales pasos, un adverbio modal podría hacer la misma función del verbo semiauxiliar. El autor distingue, muy oportunamente, tales perifrasis de las construcciones de tipo echar de menos que tienen más similitud con las frases hechas. Hace, además, una útil distinción entre impersonales reflejas (incluída la oración con un verbo transitivo con complemento directo) y pasivas reflejas. El español parece ser más claro que algunas otras lenguas románicas, por poseer el acusativo preposicional: Se oye perfectamente a los cantantes. Otras anotaciones importantes conciernen sobretodo a la componente semántica: $X$. escribe mucho. Es más ilustrativo aun el verbo beber (p. 166): no cambia el sentido sólo la presencia o la falta del objeto, sino también altera el sentido la presencia o la supresión del modal como está mostrado, oportunamente, con Alfredo bebe moderadamente/Alfredo bebe.

En las páginas dedicadas a la oración compleja querríamos un tratado más detallado sobre el uso del subjuntivo. Se precisa, si, que es obligatorio en las atributivas que expresan duda, posibilidad o actitud personal. Además, que con los verbos de comunicación el indicativo es general en la forma afirmativa, mientras aparecen el indicativo y subjuntivo en forma negativa por razones de estilo: $X$. dijo que vendria mañana. $X$. no dijo que viniese mañana. Se considera, justamente, al llamado potencial un indicativo.

En la misma página (171) hay una oración compleja problemática con el verbo oir (estamos por consiguiente en el área de los verbos sentiendi et dicendi latinos): X. oyó abrir la puerta. X. oyó a Ana abrir la puerta. Como la segunda oración tiene un neto olor de 
acc.c.inf. querríamos saber, nosotros extranjeros, si una oración tal pertenece al lenguaje coloquial.

Hace falta, por lo menos para nosotros que llegamos al español de las lenguas eslavas y tenemos en la nuestra otro sistema para concordar los paradigmas verbales, una observación sobre la concordancia de los tiempos o, dicho con la terminología latina, la consecutio temporum, saliente con más claridad, aunque no exclusivamente, en la subordinada objetiva. Todos los ejemplos que el autor cita (p. 170-171) respetan esas reglas; en un solo caso, No se ha dicho que viniese/que viene, se admite la libertad de escoger también el presente (el indicativo!). El autor se limita a precisar que "si el discurso es referido por el hablante, acomoda los tiempos", lo que no es suficiente, por cierto. No sólo porque hablan todas las gramáticas de la concordancia de los tiempos ${ }^{1}$, sino porque Gili Gaya, Curso Superior de Sintaxis Española, par. 220, hace observar que las reglas heredadas de las gramáticas y obras literarias latinas no son escrupulosamente observadas en español, especialmente cuando el sujeto de la subordinada es diferente al de la principal. Como este complejo de reglas, este sistema, o mejor dicho esta visión de las acciones o situaciones es común a las lenguas románicas -- el rumano y algunas pocas regiones italianas, las que están en contacto con el mundo eslavo, a parte - podemos presumir también violaciones análogas. Es curioso que el LRL IV (italiano) hace, a página 127, una pequeña anotación, mientras el LRL V (francés), no dice nada sobre este tema, a pesar del célebre juício apodíctico de Ferdinand Brunot, La Pensée et la Langue, (p. 782): Le chapitre de la concordance des temps se résume en une ligne: Il n'y en a pas.

6. El complejo de aportaciones que podríamos englobar bajo el título de sociolingüística está precedido del capítulo sobre la pragmalingüística, la cual no está, stricto sensu, ligada a los cambios de la sociedad, supera, todavía, un análisis meramente lingüístico. La autora destaca el problema central: tener distintos los tres niveles, sintáctico, semántico, pragmático o considerar pragmática la base de los demás. En este caso se pone el problema de justificar la existencia de un nuevo ramo. Están confrontados cuatro textos literarios españoles (Antonio Machado, Jorge Guillén, Clarín, Valle Inclán). Uno de los problemas tratados exhaustiva-mente es el de la relación entre el emisor y el receptor. Siguiendo Bakhtine se llama en ayuda el super-destinatario; en el teatro éste es el público. No sólo en el teatro: el emisor, en general, se da cuenta de los límites receptivos del interlocutor u oyente; piénsese a la poesía infantil. Por cierto, están en juego elementos paralingüísticos: tono, timbre, ritmo, entonación más o menos intencionada. Son paralingüísticos, no extralingüísticos. Y sería difícil enumerarlos todos. ¿Qué decir, por ejemplo, de la repetición de un elemento en el discurso? Un elativo como LIBER LIBER SUM nos es conocido por Horacio. Por el contrario, una repetición como la de Antonio en la oración fúnebre And Brutus is an honourable man (Julius Caesar, III/2) por ser repetida tres veces aniquila la veracidad del dicho.

1 Cf. Esbozo de la nueva gramática española de la Real Academia Española, 3.13.7. 
El complejo de estudios que podemos considerar más estrictamente sociolingüísticos abarca además del estudio introductorio, Sociolingüistica, los de Lengua y generaciones, Lengua y sexos, Tecnolectos, Jergas y también Diglosía y poliglosia, Norma y lengua estándar, Lengua y legislación. En el estudio introductorio se dan informes útiles y exhaustivos sobre los trabajos sociolingüísticos en España y en las Américas de habla española. En un punto querríamos disentir, parcialmente, de las opiniones de la autora, cuando dice (p. 263), aceptando la idea de Rona ${ }^{2}$, que "Los nuevos hábitos del habla se difunden desde las clases superiores a las inferiores y de las comunidades más modernas a las menos modernas". Para las lenguas románicas, la primera parte de la aserción es problemática, porque sabemos que las innovaciones lingüísticas en el paso del latín al romance llegaron siempre del latín coloquial, es decir de las capas bajas. Pero, si dicha aserción está limitada exclusivamente a la suerte del voseo y las oposiciones tú-vos-usted, la idea es indudablemente justa: en fin, se difundió en el latín tardio (¡no popular!) VOS en perjuicio de TU desde las capas altas de la sociedad. En el habla popular sería incomprensible no tutear a una sola persona.

En el capítulo Lengua y generaciones se insiste sobre el hecho que un estudio serio sociolingüístico no puede descuidar la edad de los encuestados. No sólo en casos obvios: sólo la generación más vieja es, eventualmente, analfabeta y por eso "más digna de fe", de habla más auténtica. Los encuestados de hoydía habían frecuentado, casi todos, la escuela, leen, siguen la TV y por esta razón el encuestado exento de influencia literaria ya no existe. Pero, los factores generacionales reaparecen de otra manera: las nuevas generaciones, hoy, están más expuestas a la influencia del inglés o del inglés de América.

En el área sociolingüística domina la aportación sobre lengua y sexos. No solamente por su extensón, (p. 276-295), sino más bien porque la autora está engagée en extremo.

Son las mismas ideas expresadas en el volumen del LRL dedicado al francés; la autora colaboró tratando el mismo argumento, con el mismo empeño. La situación en el mundo español es más propicia aun para las críticas (siempre en el campo lingüístico), siendo el machismo, según la convicción común y arraigada una de las características esenciales de la vida social en España. La autora inicia su tratado con una serie de informes históricos y demuestra como la mujer española sólo recientemente, sobre todo a partir de la II. ${ }^{\text {a }}$ República, ha podido entrar activamente en la vida social. Claro, bajo el régimen franquista tuvo lugar una nueva reducción de sus derechos. De la mitad del siglo pasado, la autora cita (p. 276), el caso de una mujer que hizo sus estudios de derecho vestida de hombre.

La autora presenta la situación de la mujer en el arco social y cultural español como absolutamente desfavorable y apoya su tesis con ejemplos convincentes. Condividimos en pleno sus convicciones. El problema, por cierto, supera límites lingüísticos. De manera general, la vieja literatura y tradición atribuye a las mujeres la culpa de casi todo: para permanecer en el ámbito literario románico, querría recordar de la literatura italiana los

2 Rona, Geografia y morfologia del voseo (1976). 
Proverbios que dicuntur super natura feminarum, del siglo XIII, quizás el primer texto misógino en romance, donde el origen de todo mal, de cada guerra que la humanidad tuvo que sufrir se encuentra en mujer, empezando con Eva en el paraíso terrestre o Helena de Troya. Parece que los hombres, mejor dicho los varones, sean seres muy débiles.

Para volver al campo lingüístico: la desigualdad de los sexos se refleja también en los idiomas. Para no repetir lo dicho ya en la reseña del volumen sobre el francés (RLiR 56, p. 197-198), querría añadir sólo que hay casos (lingüísticos) de desigualdad en todas las lenguas, probablemente. En el latín, VIRTUS proviene sin duda de VIR: semánticamente es muy distinta de la VIRTUS de la semántica cristiana y virtud romance. Para encontrar el sentido originario hay que esperar el renacentista italiano Maquiavelo y su Principe: conforme a su etimología la palabra sirve para expresar la energía, el carácter inflexible, brutal.

La autora llama los acontecimientos lingüísticos "reglas gramaticales asimétricas" y ofrece ejemplos convincentes: en el léxico español hay vocablos que en forma femenina tienen un valor negativo, mientras resultan de valor positivo o por lo menos neutro en la forma masculina. Ei fenómeno, todavía, es general: es suficiente recordar en el griego hetairos/hetaira y en el francés gars/garce.

Pues, la variante masculina, no marcada, según parece, sirve para expresar también el femenino. En un punto el español es muy categórico: la forma masculina se usa para dar idea de la pareja: los padres, los tíos, los hermanos, los reyes. Este último caso no es seguido por el italiano el cual exigiría $i$ reali di Spagna, mientras el plural masculino significa sólo más de uno de los reinantes. Tal uso es desconocido en las lenguas eslavas, ni lo conoce el francés. Aparte de designar las parejas, la costumbre de considerar la forma masculina como no marcada es general. Mala costumbre. Merece, por lo tanto, elogios el presente volumen del LRL ya que se lee en la página 1: Ursprungsgebiete, Verbreitung, Sprecher(rinen)-zahl. ¡Por desgracia!, sólo en el título.

Tercero, el eterno problema del nombre de una actividad que, estando en la forma del sustantivo, se niega o se negaba al sexo femenino: maestro/maestra no son y nunca eran problemáticos; ni señor/señora, superior/superiora, doctor/doctora, a pesar del morfema femenino no etimológico. Es posible que médica sea problemática y El País, hace algunos años, escribía regularmente la primera ministro. Es de esperar que las formas femeninas con el tiempo se impongan: la ministra de cultura declaró (Radio Exterior de España, Servicio mundial, noticiario, 1. IX. 1993; pronunciado tres veces).

Para no tachar de espiritu conservador toda la producción lingüística precedente: alcaldesa figura ya en el Diccionario de la lengua española de la Real Academia Española (16. ${ }^{a}$ edición; se declara como terminada la impresión en julio de 1936): 1) Mujer del alcalde; 2) Mujer que ejerce el cargo de alcalde. 
Y cuarto, para terminar, la autora halló una expresión muy apropiada con "asimetría sexual": analizando minuciosamente los grandes diccionarios españoles constata que, de ejemplo, hombre y mujer no tienen, los dos, el mismo valor connotativo. Si el Diccionario de Autoridades (1732) s.v. "mujer" dice: Criatura racional de sexo femenino, el Diccionario de la Real Academia Española (1984) recurre al calificativo racional y adulto sólo en el lema "hombre", el cual llega a la edad viril o adulta, mientras la mujer llega a la edad de la pubertad (v. páginas respectivamente 741 y 936). La asimetría sexual es visible también en fraseología: de unas cincuenta expresiones que contienen el elemento léxico "hombre" la mayoria tiene significado positivo, de tipo hombre de pecho, ser hombre, hacerse hombre; cuatro, en todo, son claramente negativos, como hombre de dos caras. Al contrario, de las once unidades fraseológicas con "mujer" sólo dos expresan algo positivo: mujer de digo y hago, mujer de su casa; en las demás la connotación es negativa.

La autora trata en su aportación un problema actual y eterno a la vez. Eterno, porque el problema se pone desde cuando el hombre habla. ¿Hombre? - Se pregunta ya Dante en De vulgari eloquentia (1305 o 1306) ¿quién habló primero, el hombre o la mujer? Actual, porque en nuestro siglo las mujeres han alcanzado a (casi) todas las profesiones. Los grandes cambios sociales se reflejan también en la lengua. El papel de las mujeres en la vida pública es siempre más importante: casi un tercio de los autores del volumen del LRL que estamos reseñando son autoras.

7. Los capítulos sobre tecnolectos (el título en alemán eś, quizás, más comprensible: Fachsprachen) y jergas presentan un subsistema en la lengua. Es decir, si todos los manuales lingüísticos han hablado siempre de términos técnicos, llamados en general cultismos, latinismos, voces cultas, los tecnicismos de las últimas décadas han invadido también el campo sintáctico: países no alineados. Hay que distinguir las lenguas técnicas de las jergas: éstas tienen un marcado carácter social, no sólo profesional (p. 297). Son interesantes las anotaciones sobre las influencias extranjeras en español: así, computadora, se nos asegura en la página 301, va siendo desplazada por el galicismo ordenador; claro está, en el español peninsular.

El autor hace una reseña histórica desde la época alfonsí. La más amplia es la parte dedicada al español de hoydía, donde la influencia greco-latina, aún no inmediata, es siempre actual, siendo de década a década la anglosajona, americana, la más importante en modo particular. No sorprende la ausencia de los tecnicismos y préstamos del alemán, grande en el italiano por influjo del área centroeuropea.

8. El capítulo intitulado "Diglosía y poliglosía" hace una rigurosa y justificada distinción entre bilingüismo y diglosía. Está bien presentada la situación del español que ocupa o la situación dominante frente al catalán, gallego, vasco, lenguas indígenas en Hispanoamérica, o una situación dominada como en el suroeste de los Estados Unidos. Más detalladamente, claro, tratarán los mismos problemas las partes dedicadas a las áreas hispanohablantes. 
9. Etimología y léxico cuentan con aportaciones importantes. Constatamos sobre todo que también el español espera la edición de un diccionario histórico bajo la dirección de Manuel Seco. Al igual que su análogo italiano, bajo la dirección de Max Pfister, mientras el francés ya lo posee con FEW de W. v. Wartburg. El autor del capítulo, muy razonablemente, supera los límites temporales: hablando de aitía, uno no puede empezar con la época del Renacimiento. Además, el autor no tiene en cuenta la sola etimología inmediata; además, es importante su esfuerzo de mantener distintos los conceptos de cultismo y semicultismo (cf. siglo). Eventualmente, podríamos hacer una objeción al término pseudolatinismo; el autor lo explica: no son latinismos y helenismos originarios. Existen (y forman una inmensa mayoría) los compuestos y derivados con elementos latinos y grecolatinos. Sería mejor, quizás, hablar de iberolatinismos, francolatinismos, anglolatinismos, cuando fuera posible, porque "pseudo" podría sugerir la idea errónea que sólo por una casualidad, por ser homófono un vocablo parece de proveniencia latina. Son muy correctas las observaciones sobre los dobletes, como tilde/titulo; otro gran mérito es el tener distintos no sólo préstamos y calcos, sino también calcos semánticos y calcos sintácticos.

Una atención particular se da a la creación en español, por medio de la derivación y (menos frecuentemente y limitada a la lengua técnica) de la composición. Son interesantes también algunas observaciones de menor peso, como las abreviaturas donde aprendemos, por ejemplo (p. 442), por qué uno de los trenes españoles viene llamado TALGO. Se exponen principios de etimología y si no estamos de acuerdo con el autor de que la "Etimología pueda servir para resolver problemas ortográficos", no siempre, por lo menos, estaremos plenamente de acuerdo con su idea de que la etimología, además de descubrir el origen de un vocablo, interpreta la historia cultural de una nación. Hay aportaciones lexicales prerrománicas, vocablos característicos del romance hispánico, como catar (Etymologiae de Isidoro forman una etapa obligatoria para toda búsqueda etimológica) o amarillo. Entre las aportaciones más modernas se encuentran las francesas, las inglesas y las italianas. De éstas (p. 451-452), al lado de los términos de bellas artes, de comercio y de náutica nos gustaría encontrar también los de la actividad bancaria donde figura el calco quiebra al lado del préstamo bancarrota.

10. Una pequeña parte del léxico, pequeña e importante, la forman los antropónimos y los topónimos. La historia de los nombres no es sencilla: las lenguas románicas no han heredado del latín el sistema de los tres elementos constitutivos. En la época de transición y durante largos siglos bastaba, según parece, un nombre solo para una sola persona, seguido, eventualmente, de un calificativo, del nombre del padre, del lugar o de una característica cualquiera. Desde hace siglos, la costumbre europea es la de individuar una persona por su nombre y apellido. Ahora, para nosotros extranjeros es curioso observar que el apellido en España es doble. El autor cita (p. 461), el Código civil: "Las personas son designadas por su nombre y apellidos, paterno y materno (...) apellido paterno es el primero del padre; materno, el primero de los personales de la madre aunque sea extranjera. En el Registro, uno y otro, se expresarían intercalando la copulativa $y^{\prime \prime}$. De modo que todos los españoles 
poseen dos apellidos; hay excepciones, a veces, celebérrimas, como la de Pablo Picasso (las telas antes el 1904 están firmadas también con apellido del padre).

Un segundo dato curioso, la mujer casada lleva sus propios apellidos de soltera. Lo que constituye una excepción en las demás partes de Europa en España es regla o, como dice el Código civil: "La mujer casada se designará con sus propios apellidos, aunque usare el del marido."

Se pasan en reseña nombres de pila: siendo España un país de fuerte tradición católica, no sorprende que la mayoría de ellos sean de ámbito cristiano. Si "Marías", estadísticamente, no hay tantas como, digamos, en Italia, es sólo porque en lugar de Maria se encuentra su apodo, por un normal procedimiento metonímico, quizás a causa de un tabú religioso. De aquí (María de) Dolores, Mercedes, Carmen (del monte de Carmelo), Pilar, Rosario; más de cien, dice el autor. Es útil también la lista de los hipocorísticos, en general nombres abreviados como Concha, Pili, Lola, Quico (p. 472).

Por todo lo visto se detecta la ausencia, en España, de nombres de proveniencia eslava. Es curioso, porque en Francia la moda de poner nombres de pila rusos surgió al empezarse a conocer la literatura rusa, a Dostoiewski, en manera particular. Esta moda parisiense, reforzada después de la primera guerra mundial por las olas de refugiados rusos, no atravesó los Pirineos.

11. Los topónimos están estrechamente ligados a los antropónimos. El LRL VI,1 los trata en dos capítulos, separando la toponimia española de la hispanoamericana. En el primero están presentados algunos problemas concernientes influjos fonéticos de áreas distintas del castellano, como el mozárabe en Carabanchel o el árabe en Zaragoza, Játiva (p. 477). Los topónimos interesan, a veces, a la morfosintaxis, así en los compuestos y en los que integran el nombre con el artículo.

Es de gran valor la microtoponimia, es decir, nombres de cortijos, dehesas, caminos vecinales, bosquecillos, arroyos, pozos ecc. donde se conserva más genuina la índole popular. Es que las grandes cosas, en nuestro caso los nombres de ciudades importantes, los de las arterias de una ciudad están más expuestos a los seismos de la historia. No hay que escandalizarse: la adulación a una nueva situación política o a un personaje creído carismático en una época determinada ha dado el nombre, o parte de él, a muchos topónimos. Para recurrir a una época lejana: ¿cuántas veces aparece en los topónimos romances AUGUSTUS?

El autor nos ofrece observaciones agudas: de los cambios que datan de la época franquista, dice, muchos no se impusieron en el habla; los habitantes seguían empleando los nombres tradicionales. Me sea permitido intercalar un pequeño detalle, italiano: en Nápoles existe la arteria central que lleva el nombre de Via Roma. Pero la gente de Nápoles continua llamándola Via Toledo debido al virrey de Nápoles Pedro de Toledo (siglo XVI). ¿Qué nombre tendría, hoydía, la madrileña Granvía? 
Son valiosas las anotaciones sobre las muchas deformaciones de los topónimos, debidos sobre todo a la etimología popular: Ranosa "sitio de ranas" llegó a ser Reinosa, es decir algo como "reina de las osas" (p. 477). No puedo resistir la tentación de recordar un caso análogo en la trilingüe Valcanale (región de Friuli-Venecia Julia, Italia): el topónimo esloveno Žabnice (žaba "rana"), pasado al alemán como préstamo Seifnitz, resulta calco semántico en-la versión italiana. En vez de una traducción fiel, semánticamente menos agradable, algo como ${ }^{*}$ Camporospo la etimología popular optó para una solución más poética, Camporosso.

Son significativos sociolingüísticamente los casos de tautología como en Puente de Alcántara o Minas de Almadén.

Cuando hay cambios en la toponimia, puede ocurrir lo imprevisto; léase en la página 476 la interesante historia de la lápida que decía: Plaza de Alfonso X el Sabio, antes Burro.

Una observación más: no hay muchos topónimos en -ana que abundan en Italia del Norte. No se trata de un sufijo cualquiera: -ana (en algunas partes - ac, -aco de -ACUM lat.) unido al nombre de persona, romano, forma el prediale (del lat. PRAEDIUM "propiedad de tierra") y hace patente una situación social característica en la historia.

Los topónimos hispanoamericanos tienen el valor intrínseco como indicadores de lugares determinados (p. 482); además atraen el interés lingüístico y sociolingüístico por varios motivos.

Primero, una buena parte de los topónimos son indígenas y por eso informan sobre varias áreas culturales y varias lenguas. $\mathrm{El}$ autor los examina detalladamente: algunos elementos toponímicos son transparentes, como acatl "caña", tepetl "montaña" (náhuatl) o chuqui "oro" (quechua). Otros lo son menos, para algunos la interpretación es dudosa, incierta, pero, siempre estamos en presencia de un indigenismo. El autor examinó con provecho un texto antiguo Historia general de las Indias de Francisco López de Gómara (Zaragoza, 1552) y constata, en la primera época colonial, que la mitad de los topónimos son indígenas o contienen un elemento indígena.

Aquí surge un problema sustancial: en los territorios biétnicos, y más ampliamente cuando dos etnias, y dos lenguas entran en contacto ¿en qué manera se forman los topónimos? Tres son las posibilidades: a) préstamo, es decir, aceptar, adaptando a su sistema morfonológico el topónimo de origen extranjera; b) calco, es decir, traducir el nombre de lugar; c) escoger un nombre en la propia lengua ajeno al nombre originario en cuanto al significado y a la forma fónica. Curiosamente, la segunda posibilidad, según parece, en el período de la colonización no se realizó y, como consecuencia, no hay en toponimia ni calcos ni tautologías. ¿Eran las etnías, no sólo lingüísticamente, absolutamente extrañas entre sí? La práctica más seguida, desde Colón, era la de escoger un nombre nuevo. Las motivaciones han sido varias: aspecto físico del lugar, posición geográfica, presencia de una determinada materia, vegetación, fauna. Y la más importante 
y frecuente: la personalidad del "descubridor" que se refleja en lembrarse con nostalgía de su lugar de origen, con o sin nuevo, o en mostrar su fe patriótica (Española, Fernandina; in otra parte Filipinas) o, absolutamente predominante, su fe religiosa: (Pascua) Florida, San Salvador, Asunción, Trinidad, Santa Fe, Santa Cruz y muchísimos otros.

Los topónimos no se sustraen de los acontecimientos lingüísticos generalmente válidos: elipsis del elemento sustantival: (María, reina de) Los Ángeles, posición del adjetivo connotativa o denotativa: Santo Domingo, Nueva Granada; Cabo redondo. En cuanto a las influencias de las demás lenguas europeas es interesante la observación que los inmigrantes germánicos no aportaron muchos topónimos, mientras los italianos, numerosos, sí: Nova Milano, Nova Bassano. Compárese Nova Barcelona en Voivodina, hoy Zrenjanin (cf. Linguistica XXIX, p. 102). Sí, la denominación de este tipo es fruto de un ingenuo espíritu nacionalista, comprensible y no violento. Claro, desatiende siempre la tradición indígena, y con eso hace daño. Por suerte, no todas las aspiraciones de este tipo tuvieron éxito. Es el caso de Cordón Marconi (p. 483) en Patagonia, nombre propuesto por un misionero y geógrafo italiano. Existe, sí, en Italia, en la falda de los Apeninos, un Sasso Marconi, pero éste es el lugar natal del científico italiano.

La vida social y acontecimientos históricos son importantes en toponimia: nombres de personajes ilustres han sido siempre una fuente respetable para nombres geopolíticos. Es suficiente acordarse de Colombia y América (la historia es injusta), de Bolivia, la cual debe su nombre en reconocimiento a Simón Bolívar (1825). Una consideración científica dió el nombre al Ecuador y Argentina, explica el autor, en la página 492, muestra un aspecto latinizante y literario, respecto al más antiguo Río de la Plata.

12. Las áreas hispanohablantes están presentadas condensadamente en el capítulo de introducción $\mathrm{y}$, ampliamente, en los capítulos reservados a cada una de las áreas lingüisticas: Castilla, Andalucía, Canarias, África, Estados Unidos, Islas de Caribe, México y América Central, América del Sur, Filipinas y, como colofón, "Variedades regionales del castellano en España". Es un trabajo importante de unas cien páginas.

Aquí encuentro dos problemas a los que busco respuestas.

El primero es el de judeo-español. Siendo los límites temporales del volumen el período desde el Renacimiento hasta nuestros días es comprensible que una investigación sobre, digamos, el mozárabe no tenga lugar. Mientras sí tendría lugar una sobre el judeoespañol. Con sorpresa, se encuentran sólo algunas raras alusiones fragmentarias, como las del capítulo sobre la evolucón lingüística interna (p. 428): "Por otro lado se encuentra el judeo-español $(\rightarrow 476)$, dialecto que se ha desarrollado durante quinientos años prácticamente sin contacto alguno con el terreno originario." Lo que hace pensar que esta variante del español será examinada fuera del presente volumen. Con todo, algunas veces hay notas o alusiones al judeo-español, como en el mismo capítulo cuando se habla de la coincidencia fónica de $b / v$ y se precisa que el judeo-español los distingue. Pero, se habla 
del ensordecimiento de las oclusivas intervocálicas y se descuida la situación particular del judeo-español.

El judeo-español es siempre una realidad lingüística viva del español. Su aspecto lingüístico, bastante arcaico, es muy importante para la justa valoración del español de finales del siglo XV, del de Nebrija. Además, hay un lado humano. La trágica suerte de los judíos en la Península balcánica durante la segunda guerra mundial aniquiló casi la etnia sefardí la cual, manteniendose lingüísticamente, había desarrollado una floreciente cultura. Como si no hubiese bastado la barbarie nazi, sobrevino, en Bosnia, una otra de cuya barbarie no se ve el final todavía. Algunos por suerte emprendieron su éxodo hacia Israel. ¿Quién podría saber exactamente cuántos judíos hispanohablantes se quedarán en Bosnia? ${ }^{3}$

13. El segundo problema es el del número de los hispanohablantes. En el presente volumen del LRL se leen en varias ocasiones cifras en general concordantes (de unos 400 millones), pero no en todos los autores aparecen con igual convicción. El problema no está tanto en contar los individuos hispanohablantes cuanto en delimitar el criterio. Es hispanohablante, según mi modesta opinión, quien tiene el español como lengua materna $o$, quizás mejor dicho, como lengua de la propia familia, lengua de su vida íntima. No es hispanohablante quien se sirve regularmente del español, sólo en la vida pública. Esta opinión no será, por cierto, absolutamente valida, ni siempre aplicable: hay personas que hablan con igual espontaneidad dos, quizás tres idiomas, hay incluso escritores que escriben en más de una lengua, hay también naciones o partes de una nación verdaderamente bilingües. Por ejemplo, los eslavos sorbios (en la ex-Alemania oriental) que tienen para cada significado dos significantes, uno sorbio, otro alemán; pero, sólo una de las lenguas es la lengua del individuo, una sola es la lengua del corazón; la otra es la lengua del trabajo, de la vida social. "Für die Sprecherzahl kann man grundsätzlich von den jeweiligen Einwohnerzahlen ausgehen", leemos en la página 15 y me parece un punto de partida erróneo, y peligroso. Establecer el número de los hablantes es una tarea sumamente dificil y exige una extrema circunspección. Lázaro Carreter en su Diccionario de términos filológicos, de ejemplo, s.v. español no da ningún número de hablantes: "Lengua románica nacional de España y de casi todos los pueblos que constituyeron el antiguo Imperio español. Es, pues, lengua oficial y de cultura, de unos 120 millones de personas." Bec, Manuel pratique de philologie romane, I (1970) juzga muy realisticamente el número de los hispanohablantes en unos 140 millones.

14. Los capítulos sobre las áreas hispanohablantes están hechos, todos, según un módulo simple y eficaz: cuadro geográfico, breve bosquejo histórico y situación lingüística actual con rasgos más destacados. Una bibliografía seleccionada permitirá al estudioso ampliar y profudizar su saber. Empiezan los estudios sobre las áreas hispanohablantes con las peninsulares. Surge en seguida el problema de nomenclatura: español/castellano. El LRL se sirve de manera general del término español. La elección está justificada ya en el

3 Véase VERBA HISPANICA I, Alica Knezović, Unas caracteristicas específicas del judeo-español de Sarajevo, Bosnia. 
capítulo de evolución interna: "Se prefiere aquí el término español; se utiliza su sinónimo castellano sólo donde conviene dar énfasis al contraste de este idioma con las demás hablas regionales de la Península, sea durante la Edad Media, sea en la época moderna, "(p.428). Resulta algo oscura la noción del castellano como abstracción (p. 495); por el contrario, son absolutamente acceptables las palabras de Navarro Tomás, citadas en la misma página: "Una cosa es esa forma de hablar correcta y otra muy distinta la forma de hablar castellana, que ha avanzado, por lo menos en su evolución fonética, mucho más que la forma de hablar correcta, anclada en el modelo de la lengua literaria." La vida de los idiomas nos enseña que entre la lengua escrita, literaria y el dialecto hablado, aunque sea de gente culta, no puede existir una completa concordancia. Sírvanos el italiano como caso más claro: en el dialecto toscano del Trecento, en el siglo XIV, nacieron las grandes obras literarias. En aquel entonces, el toscano era efectivamente la lengua literaria italiana. Después, la norma literaria se quedó anclada, mientras el dialecto hablado, como tal, tuvo que cambiar en muchos rasgos lingüísticos.

Lamentamos con el autor que el ALPI, Atlas Lingüístico de la Península Ibérica, no haya llegado más allá del primer tomo, presentado con gran entusiasmo a los romanistas participantes al XI Congreso internacional de lingüística y filología románicas (Madrid, 1965). Nuestro conocimiento del castellano peninsular sería mucho más exacto, si dispusiéramos de una tal obra importante.

Están muy condensados los datos históricos esenciales del paso del castellano a lengua nacional. Con la Reconquista no se concluye una época, más bien, empieza. Hay otros puntos significativos. "Con la llegada de los Borbones y del siglo XVIII," dice el autor, "la idea de la pureza de la lengua se convierte en purismo,"(p. 498). En la presentación del castellano actual se hace mención de algunas variantes fonéticas (la ̀̀ abierta). En el capítulo de morfología y sintaxis hay observaciones interesantes sobre la mayor liberalidad del habla respecto a la lengua literaria: son aceptadas las formas femeninas como sicóloga, abogada, médica "a pesar de la resistencia de algunos hablantes"(p. 501). Es decir, en el habla las formas femeninas son un hecho general. Se mencionan muchas innovaciones morfosintácticas: puramente morfológica es la presión de la analogía en los paradigmas de las conjugaciones, como crezo, merezo, conozo; son morfosintácticas las anotaciones sobre el uso del artículo determinado, sobre la tendencia a la desaparición de los comparativos sintéticos, herencia del latín. En algunos puntos la materia sintáctica está tratada menos felizmente. Nos damos cuenta, claro, de que un diccionario enciclopédico no es ni un manual de gramática ni una historia de la lengua. Sin embargo, las seis líneas sobre la suerte del subjuntivo y la constatación de su pérdida a favor del indicativo parecen poca cosa. Porque es en el habla donde esperamos, sobre todo, los cambios lingüísticos. La sintaxis en la esfera de las áreas hispanohablantes queda siempre un poco como la Cenicienta. A pesar de algunas observaciones interesantísimas: en este capítulo, por ejemplo, las del empleo del condicional en las subordinadas condicionales donde la norma literaria, y de acuerdo con ella el habla culta, exige el subjuntivo: Me compraria un coche si tendría dinero. Para el habla en Andalucía, se nos asegura en la página 517, que el módulo de un período hipotético puede ser también Si tuviera dinero, iba al cine. 
Otras observaciones sobre la sintaxis andaluza conciernen a la alteración del orden de los elementos, el adverbio modal cargado de valor negativo, falta de concordancia entre el pronombre personal átono y el sintagma a que apunta (debido a la desaparición de la $-s$ ): le dan igual "les da igual", empleos del verbo ir con varias preposiciones, competiciones entre hacer y haber en hay tiempo que no lo veo. Como, en el pronombre personal, vosotros no existe, hay un aparente desacuerdo en ustedes hacéis.

En algunas áreas lingüísticas (África, Estados Unidos) nos interesa más el lado sociolingüístico. Así leemos que en los EE.UU. hay un número considerable, 20 millones de hispanohablantes (según el censo oficial sólo 14 millones). De los cuales los más numerosos son los mexicanos como consécuencia de varias oleadas de inmigrantes. Un pequeño dato interesante: al incorporarse la región del suroeste a la Unión Americana, en 1848 , había solamente unos cien mil hispanohablantes.

15. Las áreas lingüísticas hispanohablantes que más llaman la atención, es obvio, son las de la América de habla española, repartidas entre tres grandes capitulos (Islas del Caribe, México y América Central, América del Sur). Claro está, y es válido aquí como lo es en otros lugares y como lo era para el latín en la época del imperio romano: la imagen de la lengua escrita es mucho más unitaria que la de la lengua hablada, mejor dicho, de las distintas hablas regionales.

Todos los estudios de las áreas hispanohablantes son ricos en detalles sociolingüísticos. Escojamos uno: la evangelización del Nuevo mundo. Al decreto de Felipe II del 1580 sobre el establecimiento de cátedras de lenguas indias y la prohibición de la ordenación sacerdotal de quienes no supieran las lenguas autóctonas (p. 568) se contrapone la constatación del Consejo de Indias, unos quinze años más tarde, de la "excesiva multiplicidad de lenguas indígenas con la consiguiente dificultad para explicar bien el catecismo".

En todos los tratados se aducen las distinciones respecto a la norma del español peninsular. Muchas veces habrá que buscar la razón en el sustrato indígena. El LRL, prudentemente, no sigue la visión exagerada de Rodolfo Lenz, el cual consideraba al chileno "el español con sonidos araucanos": el error fundamental de tales comparaciones es confrontar el habla de una región con la norma (ideal) de la variante literaria o estándar de una lengua. De todos modos, hay que tener en cuenta el sustrato indígena. En fonología, no hay duda de la influencia quechua en cuanto al sistema vocálico, reducido a sólo tres elementos, $i-a-u$. Otras veces, las variedades podrán ser atribuidas a la vivacidad de la lengua hablada y como tal sometida a inestabilidad, así el/la calor, azucar, f. (Perú); hambre, $\mathrm{m}$. (Argentina), ecc. Los sufijos con valor afectivo son numerosos, más que en dialectos peninsulares: mamajita; a veces aparecen dobles, -ito + -ico: chiquitico (Ecuador).

Para el pronombre personal, sin ser ni obligatorio ni dominante, se registra su uso con el verbo en las interrogaciones: ¿Qué tú quieres? (Panamá, Venezuela), ¿Por qué vos 
querés que yo diga esto? (Río de la Plata). Una atención particular ha sido reservada, en todos los estudios, al voseo y al leismo/loismo. Las observaciones sintácticas añaden nuevo material a la Sintaxis hispanoamericana de Kany. Es inútil decir que el campo de los problemas sintácticos es inconmesurable: la sintaxis en esta gran área exigiría un espacio mayor. Del verbo, por ejemplo, se encuentra muy poco: subjuntivos en -se y -ra, conservación del futuro hipotético (Colombia, Venezuela, Ecuador, Canarias), sustituciones por varias estructuras del futuro romance, sintético. Para el léxico, siendo imposible tratarlo ampliamente, están indicadas las tendencias más destacadas; es decir la influencia siempre más fuerte del anglosajón, sentida particularmente en las regiones limítrofas con los Estados Unidos y en sectores que por una u otra razón tenían y tienen conexiones más estrechas con el mundo angloamericano.

El examen de las áreas lingüísticas hispanoamericanas está muy oportunadamente completado con un sumario de las variedades regionales del castellano en España, donde unas páginas muy interesantes están reservadas a la representación del llamado español vulgar. Con el español del Nuevo mundo se constatan muchos trechos en común.

16. Para concluir. El Diccionario enciclopédico de lingüística románica, volumen reservado al español y sus realizaciones regionales, ofrece un amplio y exhaustivo panorama del saber romanístico sobre el español desde la época del Renacimiento. A parte de algunos capitulos que más especificamente se dedican a la historia, los tratados se limitan a la situación actual. Estamos por consiguiente en plena sincronía, a pesar de que algunos autores se ven obligados para iluminar mejor su exposición a extender la presentación del problema a épocas anteriores. La tarea de una enciclopedia no es la de formular ideas nuevas, sino la de presentar el punto hasta el cual llegó nuestra ciencia en la hora actual. El LRL VI,1 responde plenamente a estas exigencias y a nuestras expectativas, estimulándonos a ampliar y profundizar nuestro saber en el marco hispánico. La riquísima bibliografía seleccionada es una guía segura. Aunque la obra es fruto de la labor de unos cincuenta hispanistas, especialistas en varias direcciones, el conjunto de la obra es sustancialmente unitario: se plantean los problemas, se presenta el estado de la investigación actual, se indican, a veces, las vías de investigaciones futuras.

El lado técnico es excelente; no hay, casi, errores tipográficos. El volumen sobre el español y toda la colección - repito, el precio a parte - llegará a ser un manual indispensable. 